\title{
AL SUNNAH; \\ Telaah Segi Kedudukan Dan Fungsinya Sebagai Sumber Hukum
}

\section{Oleh:}

Moh. Turmudi *

\section{Abstrak}

Artikel ini membahas tentang tinjauan kedudukan dan fungsi sunnah terhadap al Qur'an. Dimana al Qur'an sebagai sumber ajaran Islam yang dijamin kebenaran dan keutuhan serta kemurniannya hanya mengandung kaidahkaidah syari'at Islam secara umum. Sehingga diperlukan bantuan untuk menafsirkan kaidah dan hukum yang masih universal tersebut. Ketika Nabi masih hidup permasalah yang muncul tersebut oleh para sahabat langsung bias ditanyakan kepada baginda Nabi Muhammad SAW.

Sunnah merupakan keterangan Nabi Muhammad SAW baik berupa ucapan (sunnah qauliyah), perbuatan (sunnah fi'liyah), maupun ketetapan Nabi (sunnah taqririyah). Selain itu, Sunnah juga merupakan sumber hukum kedua setetalah al Qur'an. Hal demikian itu disebabkan adanya perbedaan sifat, yaitu al Qur'an bersifat qhat'i al wurud, sedangkan sunnah bersifat dhanni al wurud. Semantara fungsi sunnah terhadap al Qur'an adalah pertama, sunnah berfungsi sebagai penguat ( $t a$ 'qid) atas apa yang dibawa al Qur'an. Kedua, fungsi sunnah sebagai penjelas (tabyin) atas apa yang terdapat dalam al Qur'an. Dan ketiga, fungsi sunnah sebagai mustaqillah atau menetapkan hukum yang belum ada hukumnya dalam al Qur'an.

Sunnah dan al Qur'an merupakan dua hal yang menyatu sebagaimana tak terpisahkan antara mubayyin dan maudhu al bayan, mufashil dan maudhu ijmal dan antara juz'i dan

\footnotetext{
*IAIT Kediri
}

Volume 27 Nomor 1 Januari 2016 
kulli. Adalah al Qur'an yang membawa syari'at secara ijmal dan sunnah yang menjelaskan sekalian juz'iinya.

Kata Kunci : Sunnah, Fungsi dan Kedudukan Sunnah, Al Quran

\section{PENDAHULUAN}

Al Quran adalah sumber syari'at Islam yang dijamin kebenarannya dan keutuhannya. Sebagai pedoman yang utama ia mengandung kaidah-kaidah umum syari'at Islam dan hukumhukum yang universal. Untuk menafsirkan kaidah-kaidah dan merumuskannya secara rinci, al Quran secara eksplisit memberikan otoritas pekerjaannya kepada Nabi Muhammad SAW. Oleh sebab itu, ketika Nabi masih hidup, para sahabatnya selalu mencari tahu tentang apa dan bagaimana tradisi atau al sunnah Nabi yang mulia guna menjadi pedoman dalam pengamalan Islam.

Perhatian yang tercurah kepada al Qur'an yang turun secara berangsur-angsur dan berhenti secara sempurna bersamaan dengan wafatnya Nabi Muhammad SAW menyebabkan para sahabatnya tidak sempat mengkodifikasi tradisi tersebut, baik di masa sesudah rasul maupun ketika rasul masih hidup. Setelah hamper satu abad dan melalui jasa khalifah Umar bn Abdul Aziz mulai itu tradisi berhasil dikodifikasi dan sejak itu itullah banyak peneliti semisal Bukhari dan Muslim yang menghasilkan kitab-kitab Hadits yang sangat mengagumkan.

Setelah tradisi itu diketahui melalui selektifitas yang ketat, ternyata masalahnya belum selesai. Kesadaran atas adanya perbedaan terutama dari segi periwayatan antara al Qur'an yang diyakini sebagai qath'I al Tsubut, dan hadits yang disepakati sebagai dhanni al wurud dan karenanya pula menjadi dhanni al tsubut, menimbulkan persolan bagaimana kedudukan dan fungsi al sunnah sebagai sumber hukum Islam setelah al Qur'an. 


\section{PEMBAHASAN}

\section{Pengertian As Sunnah}

Kata sunnah ditinjau dari segi lughawi diambil dari bahasa Arab yang berarti 'adah' atau tradisi dan kebiasaan. Dimana tradisi dan kebiasaan mencakup yang bersifat baik, buruk, ataupun terpujin dan tercela. Dengan demikian maka sunnah dalam ungkapan lain adalah al Tahriq al Mu'tadah hasanah kaanat al syyiah. ${ }^{2}$ Di dalam al Quran kata sunnah disebut secara berulang-ulang baik dalam bentuk mufra maupun dalam bentuk jama'. Pengertian menyebutkan kata sunnah dalam al Quran pada umumnya menunjuk pada pengertian lughawi sebagaimana telah disebutkan sebelumnya. ${ }^{3}$

Lafadz-lafadz sunnah juga banyak disebut dalam hadits Nabi seperti hadits Jabir ra. ${ }^{4}$ Dan hadits AbuSa'id al Khudri. ${ }^{5}$ Kedua hadits ini hadits ini diriwayatkan oleh Imam Muslim.

Maka sunnah ditinjau dari segi syara' adalah identik dengan hadits. Pengertian ini ditunjkkan oleh Muhammad 'Ajaj al Khatib. Apabila lafadz-lafadz sunnah ada dalam syara', maka maksud dari sunnah adalah sesuatu yang diperintahkan, dilarang, atau dianjurkan oleh nabi Muhammad Saw. ${ }^{6}$ Atas dasar ini, dalam dalil hukum biasanya disebut dengan al Kitab dan al Sunnah atau al Quran dan al Sunnah. Definisi yang lebih tegas ditulis oleh al Syaukuni. Yaitu sunnah bagi al syara' adalah hadits yaitu perkataan, perbuatan dan ketetapan/izin Nabi Muhammad Saw. ${ }^{7}$

\footnotetext{
Jeddah, tt., hal. 122.

${ }^{2}$ Mahmud Syalthout, Al Islam al Aqidah wa Syariah, Al Khoiroh,
}

${ }^{1}$ Al Syarif Ali Bin Muhammad Al Jurjani, Al Ta'rifat, Al Haramain, Dar Al Qalam, 1966, hal. 499.

${ }^{3}$ QS. Al Fath/48:23 dan QS. An Nisaa/4:26

4 Imam Muslim, Shahih Muslim Syarah An Nawawi, Juz II. Maktabah Dahlan, tt. Hal. 705.

${ }^{5}$ Ibid. hal 2054

${ }^{6}$ Muhammad Ajaj Al Khatib, Ushul al Hadits, Dar Al Fikr, Cet III, 1975. Hal. 18

7 Al Syaukuni, Irsyad Al Fukhul ila Tahqiq al Haq Min "Ilm al Ushul, tt. Hal 33. Terjadi perbedaan definisi di kalangan ahli hadits, ahl ushul dan ahl fiqih, perbedaan tersebut disebabkan adanya perbedaan tujuan kajian masing-masing ahli tersebut. Muhammad Ajaj Al Khatib, hal. 54. 
Uran singkat diatas menunjukkan dengan jelas bahwa sunnah merupakan salah satu nama dari dalil-dalil hukum. Apakah disebut bahwa hukum ini ditetapkan oleh keterangan Nabi baik berupa ucapan (sunnah qauliyah), perbuatan (sunnah fi'liyah), maupun ketetapan (sunnah taqririyah).

\section{Kedudukan Sunnah Terhadap Al Quran}

Allah SWT telah menurunkan syariat-syariat kepada umat manusia dengan diturunkan secra berangsur-angsur supaya menjadi pedoman hidup agar selamat baik di dunia maupun di akhirat. Syariatnya yang terakhir diturunkan bersamaan dengan Rasulnya yang terakhir pula, yaitu Nabi Muhamad Saw, terhimpun dalam sebuah kitab yang kemudian disebut Al Quran sebagai kitab suci Umat Islam. Sebagai syari'at yang terakhir, maka di al Quran telah menghimpun syari'at yang diturunkan Allah SWT sebelumnya untuk mperbaiki dan menyempurnakannya.

Sejalan dengan fungsi kerasulan Nabi Muhammad Saw. Maka jumhur muslimin meyakini bahwa segala keterangan rasulullah yang bertalian dengan syariat Allah SWT yang diriwayatkan secara shahih dai-Nya, baik berupa perkataan, perbuatan, maupun ketetapannya adalah hujjah sumber hukum dan pedoman pengamalan umat Islam.

Beberapa alasan yang lontarkan oleh jumhur muslimin diantaranya :

1. Menrima sunnah merupakan konsekuensi iman. Iman kepada kerasulan Muhammad SAW adalah salah satu bagian dari bangunan aqidah Islam. Perintah Allah SWT mengenai keimanan kepada kerasulan Muhammad, tersurat secara berulang dalam al Quran seperti dalam suarat an Nisa'/4: 136. Dalam menjelaskan fungsi kerasulannya, Nabi Muhammad SAW mendapatkan jaminan pemeliharaan Allah SWT dari kesalahankesalahan dan kealpaan-kealpaannya serta memperoleh jaminan bimbingan dan petunjuknya. Keimanan pada kerasulan Muhammad menuntut kepada I'tiqad terhadap keberadaan sunnah rasul dan menjadikannya hujjah dan 
dasar dalam memenuhi dan memanifestasikan syariat Nabi dalam kehidupan nyata.

2. Adanya keterangan-keterangan yang jelas dan tegas dalam al Quran tentang kedudukan Rasululah dalam syari'at Islam. Allah SWT menegaskan tugas kerasulan Muhammad sebagai juru baca dan pengajar al Kitab, seperti dalam QS. Ali Imran ayat 164.

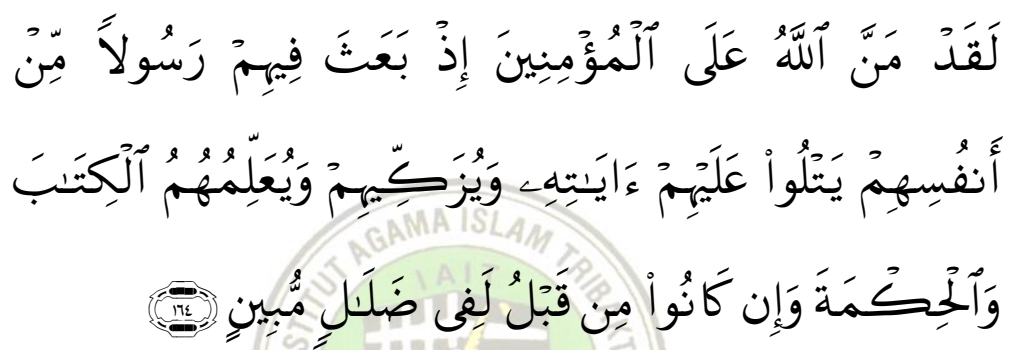

Terjemahnya : Sungguh Allah telah memberi karunia kepada orang-orang yang beriman ketika Allah mengutus diantara mereka seorang Rasul dari golongan mereka sendiri, yang membacakan kepada mereka ayat-ayat Allah, membersihkan (jiwa) mereka, dan mengajarkan kepada mereka Al kitab dan Al hikmah. dan Sesungguhnya sebelum (kedatangan Nabi) itu, mereka adalah benar-benar dalam kesesatan yang nyata. (QS. Ali Imron: 164)

Allah memberikan mandate kepada Nabi Muhammad SAW untuk memberikan penjelasan terhadap nash-nash al Qur'an. ${ }^{8}$ Kemudian Allah SWT memberikan wewenang kepada Nabi Muhammad SAW untuk menjadikan hakim dalam memutuskan perkara umat dan

\footnotetext{
${ }^{8}$ Lihat QS. An Nahl ayat 64.
} 
menjadikan kepatuhan setiap individu kepada putusan Nabi Muhammad SAW sebagai tolak ukur keimanan. ${ }^{9}$

3. Keterangan dari Rasulullah SAW sendiri tentang keharusan kaum muslimin untuk mengikuti sunnahnya, sebagaimana dijelaskan dalam hadits yang diriwayatkan oleh Al Hakim. ${ }^{10}$ Selanjutnya Abu Najih al Irbadh bin Syari'ah ra. ${ }^{11}$ yang menceritakan bahwa rasulullah SAWmemberikan nasehat kepada kita dengan suatu nasihat yang menggetarkan hati dan mencucurkan air mata, Nabi berkata yang artinya "Aku nasehatkan kepada kalian semua agar kalian bertaqwa kepada Allah, taat dan patuh, biarpun seorang hamba sahaya memerintahkan kamu. Sesungguhnya orang yang hidup lama (panjang umur) di antara kamu bakal mengetahui adanya pertentangan-pertentangan yang hebat. Oleh sebab itu hendaklah kamu berpegang teguh kepada sunnahku, sunnah khulafa'ur rasyiddin yang mendapatkan petunjuk. Gigitlah sunnah dengan taringmu, jauhilah mengada-ada perkara, sebab perkara yang diada-adakan itu adalah bid'ah, dan setiap bid'ah itu adalah tersesat dan setiap yang sesat itu neraka (tempatya)."

4. Ijma' sahabat tentang keharusan berpijak kepada Sunnah Rasul.

Para sahabat melaksanakan syari'at Islam dengan penuh kesunggguhan, kataatan dan keikhlasan tanpa membedakan antara hukum yang datang dari al Qur'an dan yang datang dari Rasul. Selain itu, para sahabat yang menjadikan sunnah rasul sebagai pijakan untuk memperoleh kejelasan dan perincian hukum dari nashnash al Qur'an yang berifat ijma'I atau umum, serta

${ }^{9}$ Ibid.

${ }^{10}$ Lihat Abu Daud, Sunnah Abi Daud, ditahqiq oleh Muhammad Muhyi Al Diin Abd. Al Hamid, Bairut Dar al Fikr, Juz IV. Hal. 200.

${ }^{11}$ Lihat Mukhtar Yahya Fatehurrahman, Dasar-dasar Pembinaan Hukum Fiqh Islam, Bandung, Al Ma'rif, 1986. Hal. 42. 
menjadikan sunnah sebagai rujukan dalam menyelesaikan urus yang hukumnya tidak tersirat dalam al Quran secara jelas.

Para sahabat pada waktu rasulullah SAW masih hidup selalu mengikuti segala yang diperintahkan oleh beliau dan menjauhi segala sesuatu yang dilarang dengan tidak membedakan antara kewajiban-kewajiban taat kepada hukum-hukum yang diwahyukan Tuhan di dalam al Qur'an, dan hukum-hukum yang ditetapkan oleh rasulullah $\mathrm{SAW}{ }^{12}$

5. Keberadaan Al Quran menjadi petunjuk kepada pentingnya kedudukan sunnah rasulullah SAW.

Sebagian besar syari'at Islam yang diturunkan oleh Allah SWT melalui wahyu al Qur'an adalah bersifat global, seperti tentang kewajiban ibadah shalat, puasa, zakat dan haji yang diungkapkan dalam bentuk perintah yang bersifat ijma'. ${ }^{13}$ Kalaupun ada penjelasan disana sini, keseluruhan hukum-hukum yang tersurat dalam nash-nash al Quran masih cukup menggambarkan persamaan dari ibadah-ibadah secara sempurna.

Dengan demikian, maka ibadah-ibadah tadi tentunya tidak mungkin dapat dilaksanakan oleh kaum muslimin dengan benar tanpa merujuk pada sunnah rasul yang berfungsi sebagai bayan syari'at Allah SWT. Sekiranya sunnah-sunnah yang berfungsi sebagai bayan ini bukan merupakan hujjah bagi kaum muslimin dan tidak menjadi undang-undang yang wajib diikuti, maka kamum muslimin tidak mengkin melaksanakan hal-hal yang difardlukan al Qur'an dan mengikuti hukum-hukumnya. Dan kewajiban mengikuti unnah-sunnah itu datangnya dari rasul dan diriwayatkan dari beliau dengan cara-cara periwayatan yang dapat meberikan kepastian atau dugaan yang kuat tentang datangnya dari rasul. ${ }^{14}$

${ }^{12}$ Ibid, hal . 13

${ }^{13}$ Ibid, hal. 43-47

14 Abdul Wahab Khallaf, Ilmu Ushul Al Fiqh, Ar Al Quwatiyyah, Mesir, Cet VIII, hal. 246 


\section{Fungsi Sunnah Teradap Al Qur'an}

Terdapat tiga fungsi sunnah terhadap Al Qur'an, pertama, sunnah menguatkan pesan-pesan hukum yang terkandung dalam al Qur'an. Kedua, sunnah menjelaskan dan menjabarkan pesan-pesan hukum tersebut. Dan ketiga, sunnah menetapkan sendiri pesan-pesan dalam hukum yang belum diatur dalam al Qur'an.

1. Fungsi Sunnah sebagai penguat (ta'kid) hukum dalam Al Qur'an.

Dalam fungsinya ini, menurut hemat penulis sunnah melakukan ta'kid (penguat) atas hukum-hukum yang terkandung dalam al Quran dengan mempergunakan beberapa cara, diantaranya sebagai berikut :

a. Menegaskan kedudukan IS hukumnya, seperti dengan sebutan wajib, fardlu dan ungkapan yang sejenisnya untuk perbuatan-perbuatan yang diperintahkan dan sebutan haram untuk kategori perbuatan yang dilarang.

b. Memerintahkan segi-segi bahasa yang timbul sebagai efek dari suatu perbuatan yang terlarang dan memperingatkan sanksi hukuman yang berat bagi pelaku perbuatan terlarang atau meninggalkan kewajiban.

c. Memperingatkan amaliyah secra dawam atas suatu kewajiban dan menampakkan suatu kebencian yang sangat terhadap suatu yang dilarang.

d. Menerangkan posisi kewajiban dan larangan dalam syari'at Islam.

Sebagai contoh sunnah yang termasuk fungsi mu'aqid, di antaranya hadits yang menta'qidkan kewajiban shalat dan puasa. ${ }^{15}$

2. Fungsi sunnah sebagai penjelas dan penjabar apa yang dibawa oleh al Qur'an.

Dalam fungsinya yang kedua ini, segi-segi tabyin (penjelas) sunnah al Qur'an antara lain:

${ }^{15}$ Abu Bakar Jabir Al Jaziri, Minhaj al Muslim, Bairut, Dar Al Fikr, Cet VII, hal 246. 
a. Mengikat makna-makna yang bersifat lepas, yang terkandung dalam ayat-ayat al Qura'an, seperti pergelangan tangan yang ditunjuk oleh sunnah sebagai penjelasan teradap "yadun" yang tedapat dalamm QS. Al Maidah ayat 38.

b. Mengkhususkan ketetapan yang disebutkan secara umum dalam nas-nas al Qur'an, seperti bayan al gharar sebagai pengecualian atas dihalalkannya jual beli yang tersebut dalam QS al Baqarah ayat 275.

c. Menjelaskn mekanisme pelaksanaan dari ketetapanketetapan al Qur'an, seperti tata cara pelaksanaan shalat, haji, puasa dan kewajiban-kewajiban lainnya.

3. Fungsi sunnah sebagai penetap hukum yang belum diatur dalam al Quran.

Dalam fungsinya yang ketiga ini, sunnah melakukan tasyri' yang boleh dikata sebagai tambahan atas hukumhukum yang tersurat dalam al Quran, seperti larangan memakan binatang buas yang bertaring dan burung yang berkaki menyambar sebagai tambahan atas empat jenis hewan yang haramkan untuk dimakan dalam al Qur'an.

Ketiga fungsi sunnah sebagaimana keterangan di atas, dua yang pertama disepakati oleh para ulama, sementarayang ketiga diperselisihkan. Adapun masalah pokok yang diperselisihkan tersebut adalah apakah sunnah dapat menetapkan hukum secara mandiri tanpa bergantung kepada al Qur'an atau penetapan itu selalu mempunyai $u s h l$ dalam al Qur'an.

Selain fungsi ketiga diatas, para ulama juga berselisih tentang fungsi sunnah sebagai nashih atas al Qur'an. Secara ringkas diterangkan oleh Abbas Mutawalli. ${ }^{16}$ Perselisihan tersebut digolongkan dalam dua kelompok yang mendukug dan yang menolak. Termasuk kedalam golongan pendukung adalah Jumhur al Mutakalimin, baik dari kalangan asy'ariah

16 Abbas Mutawalli al Hummarah, al Sunnah al Nabawiyyah wa Makanatu fi al Tasyri, Kairo, al Dar al Qammiyah li al Thiba'ah wa al Nasyr. T.th. hal 169-182. 
maupun mu'tazilah dan dari kalangan fuqaha imam malik, pengikut abu Hanifah dan Ibnu Suraij. Kelompok inipun terbagi dalam tiga kelompok. Pertama, mu'tazilah yang menyatakan sunnah dengan sifat mutawatir. Kedua, Mushab Hanafi menyatakan bahwa khabar mashur dapat menasakh ayat al Quran. Ketiga, madzhab Ibnu Hazm yang membolehkan sunnah manasakh al Qur'an meski sifatnya khabar ahad.

Adapun penolak sunnah sebagai nasakh bagi al Qur'an adalah Imam Syafi'i dan mayoritas sahabatnya serta madzhab ahl al Zhahir.

\section{Sunnah Sebagai Tasyri'}

Adalah fakta sejarah bahwa Muhammad SAW tidak saja sebagai Nabi dan Rasul, tetapi juga berperan sebagai pemimpin umat dalam berbagai aspek kehidupan manusia, yaitu aspek ideologi, politik, sosial budaya pertahanan dan keamanan. Permasalahan yang muncul diselesaikan melalui kebijakan yang dikeluarkan beliau dalam posisinya sebagai pemimpin dalam bidang politik, peperangan dan lain-lain sebagai tujuan atau misi untuk membumikan Islam. Sehingga semua perilaku beliau tanpa terkecuali mesti dapandang sebagai syariat yang mengikat semua muslim hingga sekarang.

Di dalam al Qur'an tercepat ayat-ayat yang secara jelas menyatakan bahwa diri rasulullah itu adalah figur ketauladanan. ${ }^{17}$ Bahwa setiap yang diucapkan beliau tiada lain selain ajaran Islam. Dan terdapat pula ayat yang secara tegas memerintahkan agar setiap muslim mengikuti perintah dan menjauhi segala larangannya. Namun dalam kenyetaan ditemukan adanya pengecualian-pengecualian seperti poligami, puasa wishal dan dan diwajibkannya shalat tahajud adalah khusus bagi nabi. ${ }^{18}$ Demikian pula dalam urusan keduniaan dan kenegaraan, para ahabat sejak semula telah memilih mana yang dipandang sebagai syari'at, sehingga mereka mengikuti dan mana yang dinilai sebagai hasil pikiran manusia.

${ }_{17}^{17}$ QS. Al Ahzab ayat 2.

${ }^{18}$ Zakaria al Barily, Mashadir al Islamiyah, Kairo, 1395, hal. 38. 


\section{KESIMPULAN}

Dari uraian-uraian di atas dapat ditarik beberapa kesimpulan sebagai berikut :

1. Sunnah merupakan keterangan Nabi Muhammad SAW baik berupa ucapan (sunnah qauliyah), perbuatan (sunnah fi'liyah), maupun ketetapan Nabi (sunnah taqririyah).

2. Sunnah merupakan sumber hukum kedua setetalah al Qur'an. Hal demikian itu disebabkan adanya perbedaan sifat, yaitu al Qur'an bersifat qhat'i al wurud, sedangkan sunnah bersifat dhanni al wurud.

3. Fungsi sunnah terhadap al Qur'an adalah sebagai berikut :

a. Sunnah berfungsi sebagai penguat (ta'qid) atas apa yang dibawa al Qur'an.

b. Sunnah sebagai penjelas (tabyin) atas apa yang terdapat dalam al Qur'an.

c. Sunnah sebagai mustaqillah atau menetapkan hukum yang belum ada hukumnya dalam al Qur'an.

4. Sunnahdan al Qur'anmerupakan dua hal yang menyatu sebagaimana tak terpisahkan antara mubayyin dan maudhu al bayan, mufashil dan maudhu ijmal dan antara juz'i dan kulli. Adalah al Qur'an yang membawa syari'at secara ijmal dan sunnah yang menjelaskan sekalian juz'iinya. 


\section{Daftar Rujukan}

al Barily, Zakaria. Mashadir al Islamiyah, Kairo, 1395.

al Hummarah, Abbas Mutawalli. al Sunnah al Nabawiyyah wa Makanatu fi al Tasyri, Kairo, al Dar al Qammiyah li al Thiba'ah wa al Nasyr. T.th.

Al Jaziri, Abu Bakar Jabir. Minhaj al Muslim, Bairut, Dar Al Fikr, Cet VII

Al Jurjani, Al Syarif Ali Bin Muhammad. Al Ta'rifat, Al Haramain, Jeddah, tt.

Al Khatib, Muhammad Ajaj. Ushul al Hadits, Dar Al Fikr, Cet III, 1975.

Al Syaukuni, Irsyad Al Fukhul ila Tahqiq al Haq Min 'Ilm al Ushul, tt.

Daud, Abu. Sunnah Abi Daud, ditahqiq oleh Muhammad Muhyi Al Diin Abd. Al Hamid, Bairut Dar al Fikr, Juz IV.

Fatehurrahman, Mukhtar Yahya. Dasar-dasar Pembinaan Hukum Fiqh Islam, Bandung, Al Ma'rif, 1986.

Khallaf, Abdul Wahab. Ilmu Ushul Al Fiqh, Ar Al Quwatiyyah, Mesir, Cet VIII.

Muslim, Imam. Shahih Muslim Syarah An Nawawi, Juz II. Maktabah Dahlan, tt.

Syalthout, Mahmud. Al Islam al Aqidah wa Syariah, Al Khoiroh, Dar Al Qalam, 1966. 